\title{
Editorial
}

\section{Teaching Clinical Anatomy}

\author{
Habib MA
}

Knowledge of Anatomy is always considered as scientific foundations of clinical reasoning and medical practice, and a firm foundation of basic science knowledge is considered indispensable for good clinical reasoning. It is beyond doubt that sound knowledge of Anatomy is always necessary for a proper understanding of abnormal structure and function. Owing to the shift in educational concepts the traditional way of teaching is under threat and is changing towards integrated, clinicallybased training form.

In a review study conducted in the Netherlands authors identified eight factors claimed to have a negative influence on anatomical knowledge of medical students ${ }^{1}$. Of those, decreased use of dissection as a teaching tool, decreased anatomy teaching time, inadequate assessment of anatomical knowledge and neglect of vertical integration of anatomy teaching match with Bangladeshi context. Because of shrinkage of the teaching time, question of relevancy of basic medical science has arrived. Survey conducted on the clinical practitioners of Spain revealed that gross human anatomy was considered the most relevant basic discipline for surgical specialists, while pharmacology and physiology were opined as most relevant for medical specialists $^{2}$. It was reported in India that besides human error and other factors, in surgical treatment failures, lack of anatomical knowledge was highly significant $^{3}$.

Allotted time for anatomy in undergraduate medical course is also a matter of debate. A cross-sectional, questionnaire-based study conducted at a medical university of Ireland among clinicians revealed, 80\% respondents indicated that the time dedicated to anatomy was 'sufficient', while $9 \%$ indicated that it was 'too little'. Of the anatomy educators, $50 \%$ felt that there was 'too little' time dedicated to anatomy, with remaining educators expressed satisfaction that it was sufficient ${ }^{4}$. The discrepancy of thought between providers and users must be taken into consideration. Fact is, well planned undergraduate curriculum and adding clinically relevant anatomy to clinical skills courses of residence and fellowship students will be able to produce tomorrow's doctor with adequate anatomical knowledge ${ }^{5}$. It is the time to develop context friendly curriculum. Delphi method survey involving anatomists and clinicians may be a good helping tool as used by Tubbs et $\mathrm{al}^{6}$. Anatomy course shall contain a 'core syllabus' of absolutely mandatory features identifying the minimum level of knowledge expected out of qualified medical graduates in order to carry out clinical procedures safely and effectively. A general consensus should be there to avoid overloading the students with unnecessary facts that have less immediate application to their future careers as clinicians. The curriculum, teaching and assessment must encourage the learning of clinically meaningful anatomy.

Making anatomy more clinically oriented does not mean adaptation of technology based teaching methodology, totally avoiding traditional dissection based and laboratory oriented teaching methods. It is necessarily an early establishment of a strong link in between preclinical coursework and the clinical context. Though benefit of using computer based and imaging technology is there. But those cannot be the way of making teaching anatomy for the graduate or postgraduate medical learning clinical. A survey conducted on the doctors of Israel society revealed that $657(97.6 \%)$ and $525(78.7 \%)$ doctors perceived anatomy as specifically relevant to surgeons and physicians, respectively ${ }^{7}$. They opined that anatomy teaching should be dissection-based rather than imaging-based $(P<0.001)$. That surveyor found, respondents thought that every student should use anatomy learning aids such as anatomical models, manikins and computer programs rather than use of accessory teaching methods. Prosected cadaver specimens, life models, radiological images and telescopic views of the living body together maximise learning. Interdisciplinary skills training course linking basic anatomical knowledge and clinical skills lead to clear improvement of learning outcomes for both, anatomical knowledge and clinical skills ${ }^{8}$.

Brig Gen Md Ahsan Habib, MBBS, MPhil, MMEd, Professor and Head, Department of Anatomy, AFMC, Dhaka. 
Anatomy is concerned with the structure of the body, its organs and their spatial relationships. To achieve the objective of teaching, the department of anatomy of Bangladesh Armed Forces Medical College has made an arrangement to make models available during self-study of students. The effect was scientifically studied and outcome was observed. The paper reported by the research team is published here in this issue. Simultaneous study and visualization of features by the learner had good impact on learning anatomy. It not only helps the students to understand the spatial relation but also making the subject relevant and interesting. It was noticed in the mentioned study that both teachers as well as students were in favour of making the models more available which were locally made at the department and observed positive impact on performance in examination $(p<0.000)$. It is expected that the paper will be able to draw the attention of professionals.

\section{References}

1. Bergman EM, Verheijen IW, Scherpbier AJ et al. Influences on anatomical knowledge: The complete arguments. Clinical Anatomy 2014; 27(3):296-303.

2. Arráez-Aybar LA, Sánchez-Montesinos I, Mirapeix $\mathrm{RM}$ et al. Relevance of human anatomy in daily clinical practice. Annals of Anatomy 2010; 192(6):341-8.
3. Singh R, Tubbs RS. Should a Highly Skilled Surgeon be an Advanced Anatomist first?- A View Point. Basic Sciences of Medicine 2015; 4(4):53-7.

4. Sbayeh A, Qaedi Choo MA, Quane KA et al. Relevance of anatomy to medical education and clinical practice: Perspectives of medical students, clinicians and educators. Perspect Med Educ 2016; 5(6):338-46.

5. Turney BW. Anatomy in a Modern Medical Curriculum. Ann R Coll Surg Engl 2007; 89(2):104-7.

6. Tubbs RS, Sorenson EP, Sharma A et al. The development of a core syllabus for the teaching of head and neck anatomy to medical students. Clinical Anatomy 2014; 27(3):321-30.

7. Marom A, Tarrasch R. On behalf of tradition: An analysis of medical student and physician beliefs on how anatomy should be taught. Clinical Anatomy 2015; 28(8):980-4.

8. Rafai N, Lemos M, Kennes LN et al. Anatomy meets dentistry! Linking anatomy and clinical practice in the preclinical dental curriculum. BioMed Centre Medical Education 2016; 16(1):305. 